\title{
Prediksi Kepuasan Tenant Pada Gedung Wisma Keiai Menggunakan Algoritma C4.5
}

\author{
Nurul Afni ${ }^{1}$, Melan Susanti ${ }^{2}$, Zulfajri $^{3}$ \\ ${ }^{1}$ Universitas Bina Sarana Informatika \\ e-mail: ${ }^{1}$ nurul.nrf@bsi.ac.id \\ 2,3STMIK Nusa Mandiri \\ e-mail: 2 melan.msu@nusamandiri.ac.id, ${ }^{3}$ zulfajri75@gmail.com,

\begin{tabular}{ccc}
\hline Diterima & Direvisi & Disetujui \\
$04-11-2020$ & $09-11-2020$ & $15-12-2020$ \\
\hline
\end{tabular}

\begin{abstract}
Abstrak - Prediksi kepuasan tenant terhadap gedung yang akan disewa sangat dibutuhkan perusahaan penyedia jasa termasuk building management pada Gedung Wisma Keiai. Dengan adanya prediksi kepuasan tenant dapat membantu manajemen untuk meningkatkan kepuasan tenant di gedung tersebut. Penelitian ini bertujuan untuk menganalisis kepuasan Tenant pada gedung Wisma Keiai dengan menggunakan teknik data mining dengan metode algoritma C4.5. Atribut yang akan digunakan sebagai masukan kepuasan tenant dalam penelitian ini mencangkup fasilitas gedung, pelayanan dan daya tanggap. Dalam penelitian ini, didapatkan bahwa hasil yang didapatkan berasal dari beberapa atribut masukan menghasilkan hubungan sebab-akibat dalam mengklasifikasikan konsumen puas dan tidak puas. Penelitian ini diharapkan dapat membantu pihak Gedung Wisma Keiai dalam meningkatkan kepuasan tenant untuk mempertahankan tenant dan meningkatkan keuntungan perusahaan tersebut. Data kuisioner sebanyak 50 tenant yang didapat dari penilaian tenant di Gedung Wisma Keiai yaitu 41 tenant puas dan 9 tenant tidak puas. Berdasarkan hasil perhitungan klasifikasi menggunakan algoritma C4.5 menunjukkan bahwa diperoleh akurasi mencapai $100.00 \%$ yang menunjukkan bahwa algoritma C4.5 cocok digunakan untuk mengukur tingkat kepuasan tenant di Gedung Wisma Keiai.
\end{abstract}

Kata Kunci: Data Mining, Kepuasan Tenant, Algoritma C4.5

\begin{abstract}
Prediction of tenant satisfaction with the building to be rented is very much needed by service providers, including building management at the Wisma Keiai Building. With the prediction of tenant satisfaction, it can help management to increase tenant satisfaction in the building. This study aims to analyze tenant satisfaction at the Wisma Keiai building using data mining techniques with the C4.5 algorithm method. The attributes that will be used as input for tenant satisfaction in this study include building facilities, services and responsiveness. In this study, it was found that the results obtained came from several input attributes resulting in a causal relationship in classifying satisfied and dissatisfied consumers. This research is expected to help the Wisma Keiai building in increasing tenant satisfaction to maintain tenants and increase the company's profits. Questionnaire data of 50 tenants obtained from the tenants assessment at Wisma Keiai Building, namely 41 satisfied tenants and 9 dissatisfied tenants. Based on the results of classification calculations using the C4.5 algorithm, it shows that the accuracy reaches $100.00 \%$, which indicates that the C4.5 algorithm is suitable for measuring the level of tenant satisfaction at Wisma Keiai Building.
\end{abstract}

Keywords : Data Mining, Tenant Satisfaction, Algorithm C4.5

\section{PENDAHULUAN}

Tenant merupakan orang yang menilai baik tidaknya kualitas pelayanan. Tenant menilai pelayanan tersebut dengan cara membandingkan dengan pelayanan yang mereka terima dengan pelayanan yang mereka harapkan. Bila tenant merasa sangat puas terhadap pelayanan yang diberikan oleh suatu gedung akan mengakibatkan tenant tersebut akan tetap berada di gedung tersebut karena pelayanan yang diberikan sangat bagus. Dengan kata lain perusahaan yang dapat memuaskan tenant akan memiliki tenant yang loyal. Pada saat ini industri jasa building manajement semakin banyak di Jakarta. Gedung Wisma Keiai di Jakarta merupakan salah satu badan usaha yang mengkonsentrasikan salah satu bidang usahanya dibidang jasa penyewaan ruang kantor. Sebagai 
suatu perusahaan swasta tentu saja hadir untuk mendapatkan keuntungan sekaligus memberikan pelayanan yang memuaskan bagi tenant. Akan tetapi bukan hanya Gedung Wisma Keiai saja yang bergerak di bidang building management, pelayanan ini sehingga hal ini menimbulkan persaingan antar perusahaan yang bergerak di bidang ini. Layanan yang diberikan kepada penghuni apartemen harus sejalan dengan keinginan dan harapan penghuni. Oleh karena itu, pihak manajemen harus mampu menangani kebutuhan pelanggan sehingga dapat mengurangi jumlah keluhan dari pelanggan yang dapat menyebabkan terjadinya konflik (Irfiani, 2014).

Ada enam alasan mengapa suatu institusi perlu mempertahankan loyalitas pelanggannya. Pertama: pelanggan yang ada lebih prospektif, artinya pelanggan yang loyal akan memberikan keuntungan yang besar kepada institusi. Kedua: biaya mendapatkan pelanggan yang baru jauh lebih besar dibandingkan menjaga dan mempertahankan pelanggan yang sudah ada. Ketiga: pelanggan yang sudah percaya pada institusi dalam suatu urusan akan percaya dalam urusan lain. Keempat: biaya operasai institusi akan menjadi efisien jika memiliki banyak pelanggan yang loyal. Kelima: institusi dapat mengurangkan biaya psikologis dan social dikarenakan pelanggan yang lama telah mempunyai banyak pengalaman positif dengan institusi. Keenam: pelanggan yang loyal akan selalu membela institusi bahkan berusaha pula untuk menarik dan memberi saran kepada orang lain untuk menjadi pelanggan (Santoso, 2011). Data mining adalah serangkaian proses untuk menggali nilai tambah berupa informasi yang selama ini tidak diketahui secara manual dari suatu basis data, informasi yang dihasilkan diperoleh dengan cara mengekstraksi dan mengenali pola yang penting atau menarik dari data yang terdapat pada basis data (Vulandari, 2017). Selain itu data mining dapat digunakan untuk langkah analisis terhadap proses penemuan pengetahuan di dalam basis data atau knowledge discovery in databases yang disingkat KDD, pengetahuan bisa berupa pola data atau relasi antar data yang valid (yang tidak diketahui sebelumnya) (Suyanto, 2017). Penyewaan gedung Wisma Keiai dalam memperbaiki pelayanan terhadap tenant membutuhkan penelitian untuk mengetahui hal-hal yang mempengaruhi kepuasan tenant. Dalam hal ini data mining dengan algoritma $\mathrm{C} 4.5$ akan digunakan dalam prediksi kepuasan tenat pada gedung Wisma Keiai.

Algoritma yang disebut "aturan C4.5" dimulai dengan membangun pohon keputusan dan mengubahnya menjadi aturan klasifikasi yang kompatibel, tetapi kemudian aturan tersebut unduk pada proses penyederhanaan (pemangkasan), yang secara signifikan dapat mengubah fungsi keputusan dari model. Aturan pemangkasan dilakukan dengan menghapus tempat jika tanpa mereka klasifikasi ulang tidak memburuk. Setiap aturan disederhanakan secara terpisah, sehingga aturan yang dihasilkan berdasarkan klasifikasi mungkin berbeda secara signifikan dari pohon asli (dalam praktiknya, biasanya kurang akurat) (Grabczewski, 2014). Algoritma C4.5 adalah bagian dari algoritma untuk klasifikasi dalam pembelajaran machine learning dan data mining. C4.5 merupakan algoritma yang cocok digunakan untuk masalah klasifikasi pada machine learning dan data mining" (Christie, Baskoro, Ambarwati, \& Wicaksana, 2013). Algoritma C4.5 merupakan salah satu solusi pemecahan kasus yang sering digunakan dalam pemecahan masalah pada teknik klasifikasi. Keluaran dari algoritma C4.5 itu berupa sebuah decision tree layaknya teknik klasifikasi lain. Sebuah pohon keputusan adalah sebuah struktur yang dapat digunakan untuk membagi kumpulan data yang besar menjadi himpunan-himpunan record yang lebih kecil dengan menerapkan serangkaian aturan keputusan. Dengan masing- masing rangkaian pembagian, anggota himpunan hasil menjadi mirip satu dengan yang lain.

Pada penelitian ini penulis memulai dari tahap mengidentifikasi masalah, hipotesis, pengolahan data melalui survey dengan mengajukan pertanyaan-pertanyaan dalam bentuk kuisioner yang melibatkan factor - faktor yang mempengaruhi kepuasan pelanggan untuk menyesuaikan pelayanan yang lebih baik hingga sesuai dengan yang diharapkan pelanggan, analisa data dan menarik kesimpulan.

\section{METODE PENELITIAN}

Adapun metode penelitian yang penulis lakukan didalam melakukan prediksi kepuasan tenant digedung wisma keiai menggunakan algoritma C4.5 ditunjukkan pada gambar dibawah ini:

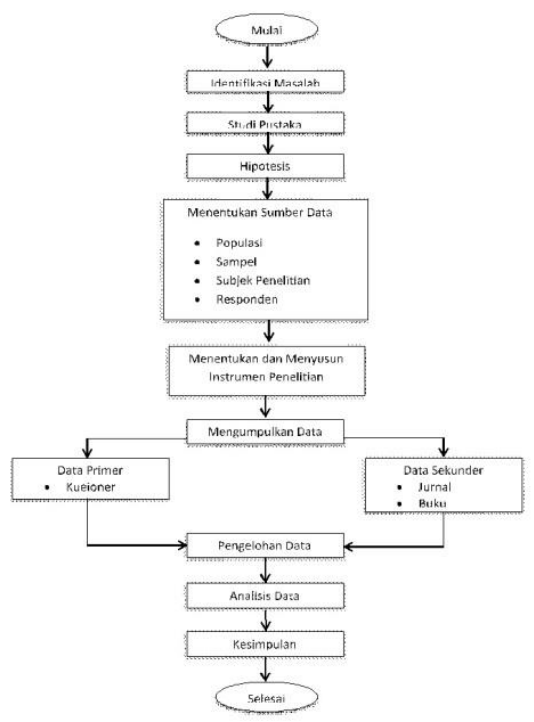

Gambar 1. Skema Penelitian

Berdasarkan Gambar 1. menentukan skema kegiatan penelitian hingga mendapatkan kesimpulan. 


\section{a. Instrument Penelitian}

Berdasarkan rumusan masalah yang yang telah dijabarkan, maka alat dan bahan yang dibutuhkan untuk penelitian ini antara lain:

1. Bahan

Dalam penelitian ini menggunakan data penilaian kepuasan tenant di gedung Wisma Keiai

2. Peralatan

Pada penelitian yang dilakukan untuk menyelesaikan penelitian ini, instrumen peralatannya yang berupa software dan hardware.

b. Metode Pengumpulan data, Populasi dan sample Penelitian

Metode pengumpulan data yang digunakan dalam penelitian ini menggunakan metode Studi Pustaka (Library Research Method). Metode ini metode yang digunakan untuk mendapatkan data yang dibutuhkan mencari informasi mengenai pengolahan data baik dari buku-buku, laporan penelitian maupun jurnal dari internet.

1. Data Primer

Data primer diperoleh secara langsung dari sumber data yang berhubungan dengan penelitian yang dilakukan yaitu Prediksi kepuasan tenant gedung Wisma Keiai

2. Data Sukunder

Data sekunder sebagai pelengkap data primer yang diperoleh dari buku-buku, jurnal ilmiah, publikasi, laporan penelitian dan internet untuk menunjang landasan teori. Pada metode ini kegiatan yang dilakukan adalah mempelajari, mencari dan mengumpulakan data-data yang berhubungan dengan prediksi kepuasan tenant yang diperoleh dari gedung Wisma Keiai. Data yang telah diperoleh kemudian akan diolah menggunakan metode klasifikasi algoritma C4.5 dengan mengambil nilai dari setiap atribut pada data untuk menentukan tenant mana saja yang sudah puas dengan pelayanan yang diberikan oleh gedung tersebut.

\section{c. Metode Analisa Data}

Analisis data merupakan suatu proses mencari dan menyusun decara sistematis data yang telah diperoleh dari wawancara, dokumentasi, dukumen pribadi, observasi, catatan lapangan, gambar foto dan lain sebagainya, dengan cara meng organisasikan data tersebut kedalam kategori, menjabarkan kedalam unit-unit, melakukan sintesa, menyusun kedalam pola, memilih mana yang penting dan mana yang akan dipelajari dan kemudian membuat kesimpulan agar dapat dipahami diri sendiri maupun orang lain.

Dalam penulisan penelitian ini menggunakan analisis data kualitatif yaitu analisis yang dilakukan dengan mengelompokan data untuk mencari suatu pola dari hal-hal yang dipelajari dan membandingkannya dalam konsep yang ada didalam sumber.Adapun data tenant yang akan disurvey sebanyak 50 tenant meliputi: Epson, Kopi Kenangan, Family Mart, Fruitology, JAL, Secom, Nitsu Lemo, Apotik Century, Jalan Tour, Ramen Shop Men Men, JKMC, Clinique Suisse, Kobelco, Lotte Capital, JCC, Asahi, WFP, Isse Foods, Anabuki Kosan, JRC, Nakagawa, BKS, JDS, BTS, Sakuma, Fujitsu, Shinatomo, JTB, Reeracoen, Tomoe, Chori, Idemitsu, Mega Cosultindo Perdana, Buana Restu Properti, Sukses Perdana Prima, Sekisui, Equator, JPP, JVC Kenwood, Yomiuri, Yamato, Yoshino Gypsum, Lotte Member, Mitra Lestari Sportindo, Nagase, Surya Persada Tirta, JJC, MSM, Orix dan BNC.

Waktu penelitian kurang lebih selama 4 bulan. Dari data kuisioner sebanyak 50 lembar yang didapat dari data penilaian tenan digedung Wisma Keiai terdapat 41 PUAS dan 9 TIDAK PUAS. Menurut Jefri secara umum Algoritma C4.5 untuk membangun pohon keputusan adalah sebagai berikut (Kamagi \& Hansun, 2014):

1. Pilih atribut sebagai akar

2. Buat cabang untuk masing-masing nilai

3. Bagi kasus dalam cabang

4. Ulangi proses untuk masing-masing cabang sampai semua kasus pada cabang memiliki kelas yang sama.

Rumus yang digunakan untuk menghitung pengolahan data tersebut dibagi 2 yaitu :

1. Rumus untuk menghitung Entropy

Entropy adalah jumlah bit yang diperkirakan dibutuhkan untuk dapat mengekstrak suatu kelas (+ atau -) dari sejumlah data acak pada ruang sample $S$ (Kusrini \& Luthfi, 2009)

$\operatorname{Entropy}(S)=\sum_{i=1}^{n}-p i * \log _{2} p i$

Keterangan:

$\mathrm{S}=$ himpunan kasus

$\mathrm{n}=$ jumlah partisi $\mathrm{S}$

pi $=$ probabilitas yang didapat dari jumlah (ya/tidak) dibagi total kasus

\section{Rumus untuk menghitung Gain}

Gain adalah salah satu atribut selection measure yang digunakan untuk memilih tes atribut setiap node pada tree. Atribut dengan information gain tertinggi dipilih sebagai test atribut dari suatu node (Kusrini \& Luthfi, 2009).

$\operatorname{Gain}(S, A)=\operatorname{Entropy}(s)-\sum_{i=1}^{n}-\frac{|S i|}{|S|} * \operatorname{Entropy}(s i) \ldots$

Keterangan:

$\mathrm{S}=$ himpunan kasus

$\mathrm{A}=$ Atribut

$\mathrm{n}=$ jumlah partisi atribut $\mathrm{A}$

$|\mathrm{Si}|=$ jumlah kasus pada partisi ke-i

$|\mathrm{S}|=$ jumlah kasus dalam $\mathrm{S}$ 


\section{HASIL DAN PEMBAHASAN}

\section{Pengolahan Data}

Data yang digunakan dalam penelitian ini berupa dari kuisioner. Data yang diperoleh dari pembagian kuisioner sebanyak 50 lembar kuisioner. Data yang dikumpulkan yaitu data kuisioner yang terdapat dari hasil penilaian kepada tenant tenant digedung Wisma Keiai dengan atribut nama tenant, fasilitas Gedung, pelayanan dan daya tanggap.

Kuisioner yang dibagikan ke tenant-tenant dijelaskan pada tabel dibawah ini:

Tabel 1. Keterangan Data Kuisioner

\begin{tabular}{|l|l|}
\hline Nama Tenant & Atribut yang difungsikan sebagai ID \\
\hline Lantai & $\begin{array}{l}\text { Atribut ini yang menginformasikan } \\
\text { nama tenant }\end{array}$ \\
\hline Periode & $\begin{array}{l}\text { Atribut ini yang menginformasikan } \\
\text { masa penilaian }\end{array}$ \\
\hline $\begin{array}{l}\text { Fasilitas } \\
\text { Gedung }\end{array}$ & $\begin{array}{l}\text { Atribut ini yang menginformasikan } \\
\text { jawaban pelanggan tentang pertanyaan } \\
\text { dalam kategori Fasilitas Gedung }\end{array}$ \\
\hline Pelayanan & $\begin{array}{l}\text { Atribut ini yang menginformasikan } \\
\text { jawaban pelanggan tentang pertanyaan } \\
\text { dalam kategori Pelayanan }\end{array}$ \\
\hline $\begin{array}{l}\text { Daya } \\
\text { Tanggap }\end{array}$ & $\begin{array}{l}\text { Atribut ini yang menginformasikan } \\
\text { jawaban pelanggan tentang pertanyaan } \\
\text { dalam kategori Daya Tanggap }\end{array}$ \\
\hline Masukan & $\begin{array}{l}\text { Atribut ini yang menginformasikan } \\
\text { komentar dan masukan dari setiap } \\
\text { tenant }\end{array}$ \\
\hline Kepuasan & $\begin{array}{l}\text { Atribut ini yang menginformasikan } \\
\text { Tenant Puas atau Tidak Puas }\end{array}$ \\
\hline
\end{tabular}

Dari tabel tersebut maka dipilih atribut yang akan digunakan, yang tercantum dalam tabel berikut:

Tabel 2. Pemilihan Atribut

\begin{tabular}{|l|l|l|}
\hline Atribut & \multicolumn{2}{|l|}{ Detail Penggunaan } \\
\hline Nama Tenant & $\sqrt{ }$ & ID \\
\hline Lantai & $\mathrm{x}$ & No \\
\hline Periode & $\mathrm{x}$ & No \\
\hline Fasilitas Gedung & $\sqrt{ }$ & Variabel Bebas \\
\hline Pelayanan & $\sqrt{ }$ & Variabel Bebas \\
\hline Daya Tanggap & $\sqrt{ }$ & Variabel Bebas \\
\hline Masukan & $\mathrm{x}$ & No \\
\hline Kepuasan & $\sqrt{ }$ & Label Target \\
\hline
\end{tabular}

\section{Hasil}

\section{Mencari Nilai Atribut}

Untuk mengetahui puas atau tidak puasnya tenant, maka dilakukan dpencarian nilai kepuasaan tiap atribut dengan perhitungan sebagai berikut :

$=$ IF (Nilai Angka yang dimasukkan<50,'Tidak Puas","Puas")
Hasil yang didapatkan dari kuisioner yang dibagikan diperoleh nilai kepuasan tiap atribut yang dirangkum dalam Tabel 3:

Tabel 3. Hasil Penilaian

\begin{tabular}{|l|c|c|c|c|}
\hline \multicolumn{1}{|c|}{$\begin{array}{c}\text { Nama } \\
\text { Tenant }\end{array}$} & $\begin{array}{c}\text { Nilai } \\
\text { Fasilitas } \\
\text { Gedung }\end{array}$ & $\begin{array}{c}\text { Nilai } \\
\text { Pelayanan }\end{array}$ & $\begin{array}{c}\text { Nilai Daya } \\
\text { Tanggap }\end{array}$ & $\begin{array}{c}\text { Rekomen } \\
\text { dasi }\end{array}$ \\
\hline Epson & 75 & 50 & 75 & Puas \\
\hline $\begin{array}{l}\text { Kopi } \\
\text { Kenangan }\end{array}$ & 50 & 65 & 75 & Puas \\
\hline Family mart & 75 & 83 & 50 & Puas \\
\hline Fruitology & 25 & 34 & 100 & Tidak Puas \\
\hline JAL & 75 & 83 & 75 & Puas \\
\hline Secom & 75 & 50 & 75 & Puas \\
\hline Nitsu Lemo & 25 & 33 & 25 & Tidak Puas \\
\hline $\begin{array}{l}\text { Apotik } \\
\text { Century }\end{array}$ & 25 & 33 & 25 & Tidak Puas \\
\hline Jalan Tour & 25 & 66 & 75 & Puas \\
\hline$\ldots$ & $\ldots$ & $\ldots$ & $\ldots$ & $\ldots$ \\
\hline MSM & 100 & 87 & 75 & Puas \\
\hline Orix & 75 & 100 & 100 & Puas \\
\hline BNC & 100 & 100 & 100 & Puas \\
\hline
\end{tabular}

\section{Mencari Nilai Nilai Entropy dan Gain}

Menghitung jumlah data, jumlah puas dan jumlah tidak puas serta entropy semua kasus yang dibagi per masing-masing atribut, lalu dilanjutkan perhitungan untuk masing-masing atribut.

Hitung Entropy Total :

$=(-41 / 50 *$ LOG $2(41 / 50))+(-9 / 50 *$ LOG $2(9 / 50))$

$=2.936845362$

Hitung Entropy Puas pada Fasilitas Gedung $=(-36 / 37 * \operatorname{LOG} 2(36 / 37))+(-1 / 37 *$ LOG2 $(1 / 37))$ $=24.61974$

Hitung Entropy Tidak Puas pada Fasilitas Gedung $=(-5 / 13 * \operatorname{LOG} 2(5 / 13))+(-8 / 13 * \operatorname{LOG} 2(8 / 13))$ $=1,157576709$

Hitung Entropy Puas pada Pelayanan $=(-37 / 37 * \operatorname{LOG} 2(37 / 37))+(-0 / 37 * \operatorname{LOG} 2(0 / 37))$ $=0$

Hitung Entropy Tidak Puas pada Pelayanan $=(-4 / 13 *$ LOG $2(4 / 13))+(-8 / 13 *$ LOG $2(9 / 13))$ $=1,485922257$

Hitung Entropy Puas Pada daya tanggap $=(-41 / 46 *$ LOG2 $(41 / 46))+(-5 / 46 *$ LOG2 $(48 / 46))$ $=5,402931495$

Hitung Entropy Tidak Puas Pada daya tanggap $=(-0 / 4 * \operatorname{LOG} 2(0 / 4))+(48 / 4 * \operatorname{LOG} 2(4 / 4))$ $=0$ 
Perhitungan Gain :

Hitung Gain Fasilitas Gedung

$=-(2,936845362$ -

$(37 / 50 * 24,61974)+(13 / 50 * 1,157576709))$

$=14,9807923$

Hitung Gain Pelayanan Gedung $=(2,936845362-(37 / 50 * 0)+(3 / 50 * 1,485922257))$ $=0$

Hitung Gain Daya Tanggap $=(2,936845362-(46 / 50 * 5,402931495)+(4 / 50 * 0))$ $=0$

\section{Pengolahan Data Menggunakan Rapidminer}

Pada tahap selanjutnya data akan di proses menggunakan bantuan Tools Rapid Miner, maka data akan dilihat nilai akurasi, pohon keputusan, dan rulenya. Berikut adalah data yang akan di import ke dalam RapidMiner:

Tabel 4. Data yang akan diimport ke dalam Rapidminer

\begin{tabular}{|l|c|c|c|c|}
\hline $\begin{array}{l}\text { Nama } \\
\text { Tenant }\end{array}$ & $\begin{array}{c}\text { Fasilitas } \\
\text { Gedung }\end{array}$ & Pelayanan & $\begin{array}{c}\text { Daya } \\
\text { Tanggap }\end{array}$ & Rekomendasi \\
\hline Epson & 1 & 1 & 1 & PUAS \\
\hline $\begin{array}{l}\text { Kopi } \\
\text { Kenangan }\end{array}$ & 1 & 1 & 1 & PUAS \\
\hline $\begin{array}{l}\text { Family } \\
\text { mart }\end{array}$ & 1 & 1 & 1 & PUAS \\
\hline Fruitology & 0 & 0 & 1 & Tidak puas \\
\hline JAL & 1 & 1 & 1 & PUAS \\
\hline Secom & 1 & 1 & 1 & PUAS \\
\hline Nitsu Lemo & 0 & 0 & 0 & Tidak puas \\
\hline $\begin{array}{l}\text { Apotik } \\
\text { Century }\end{array}$ & 0 & 0 & 0 & Tidak puas \\
\hline Jalan Tour & 0 & 1 & 1 & PUAS \\
\hline & $\ldots$ & $\ldots$ & $\ldots$ & $\ldots$ \\
\hline MSM & 1 & 1 & 1 & PUAS \\
\hline Orix & 1 & 1 & 1 & PUAS \\
\hline BNC & 1 & 1 & 1 & PUAS \\
\hline
\end{tabular}

Selanjutnya proses pengolahan data menggunakan algortima C4.5 untuk melihat pohon keputusan dan rule.

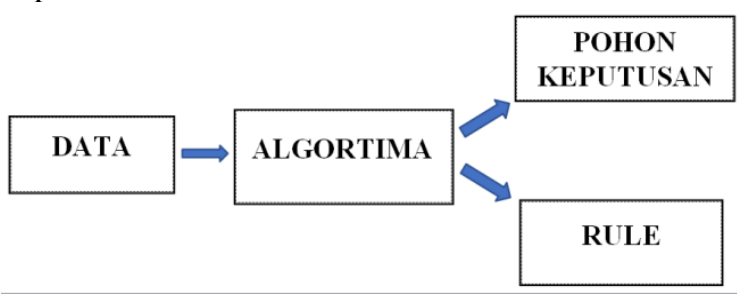

Gambar 2. Alur Pengolahan Data

Proses pengolahan data meggunakan algortima $\mathrm{C} 4.5$ untuk mendapatkan pohon keputusan dan rule pada rapidminer

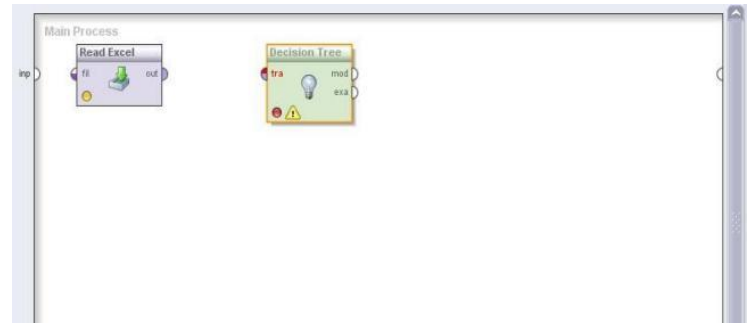

Gambar 3. Proses Pengolahan Data Pada Rapidminer

Setelah dilakukan perhitungan metode algoritma C4.5 pada Rapid Miner, maka terbentuk pohon keputusan seperti berikut :

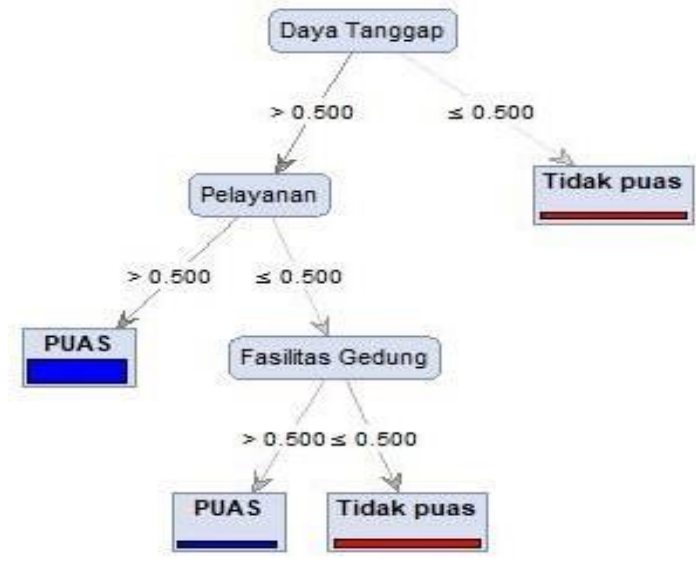

Gambar 4. Pohon Keputusan

Berdasarkan Gambar 4. menghasilkan rule yang akan diimplementasikan pada program. Rule yang dihasilkan sebagai berikut:

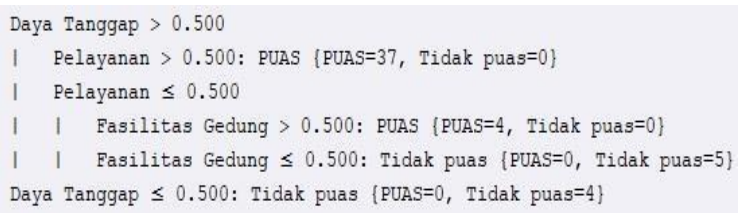

Gambar 5. Hasil Rule Rapidminer

Setelah didapatkan hasil rule maka didapatkan pula hasil kesimpulan dari pengukuran akurasi terhadap kinerja algortima C4.5 dalam prediksi kepuasan tenant di Gedung Wisma Keiai yaitu akurasi $100,00 \%+\-100$

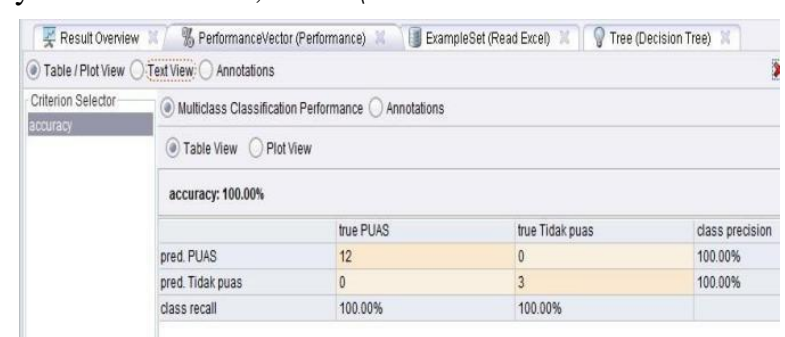

Gambar 6. Hasil Kesimpulan Akurasi Kinerja Algortima C. 45 


\section{KESIMPULAN}

Dari hasil penelitian yang telah dilakukan, maka dapat disimpulkan bahwa kepuasan tenant di gedung Wisma Keiai dapat diprediksi dan dievaluasi dengan memanfaatkan teknik data mining menggunakan Algoritma C4.5 untuk memprediksi (menentukan kelas) dari kepuasan pelanggan. Hasil pengujian prediksi kepuasan dengan rapidMiner diperoleh akurasi sebesar $100 \%$.

Untuk meningkatkan kinerja dan menyempurnakan hasil yang telah didapat diharapkan penelitian selanjutnya dapat mengembangkan dengan menggabungkan atau membandingkan dengan algortima klasifikasi lain. Dapat juga dengan menambahkan kriteria yang digunakan seperti kemudahan lahan parkir dan kebersihan pantry dan toilet. Jumlah data kuisioner ditambah, sehingga dapat diperoleh hasil akurasi fungsi algoritma yang lebih baik.

\section{REFERENSI}

Christie, D. A., Baskoro, D. A., Ambarwati, L., \& Wicaksana, I. W. S. (2013). Belajar Data Mining Dengan Rapid Miner. Jakarta: Gramedia Pustaka Utama.

Grabczewski, K. (2014). Meta-Learning in Decision Tree tnduction. Studies in Computational Intelligence. https://doi.org/10.1007/978-3319-00960-5

Irfiani, E. (2014). Prediksi Keluhan Pelanggan Pada Apartemen Menggunakan Algoritma C4.5. Jurnal Paradigma, XVI(2), 13-20.

Kamagi, D. H., \& Hansun, S. (2014). Implementasi Data Mining dengan Algoritma C4.5 untuk Memprediksi Tingkat Kelulusan Mahasiswa. Jurnal ULTIMATICS, 6(1), 15-20. https://doi.org/10.31937/ti.v6i1.327

Kusrini, \& Luthfi, E. T. (2009). Algoritma Data Mining. Yogyakarta: Andi.

Santoso, T. B. (2011). Analisa Dan Penerapan Metode C4.5 Untuk Prediksi Loyalitas Pelanggan. Jurnal Ilmiah Fakultas Teknik LIMIT'S, 10(1).

Suyanto. (2017). Data Mining Untuk Klasifikasi dan Klasterisasi Data. Bandung: Informatika Bandung.

Vulandari, T. R. (2017). Data Mining, Teori dan Aplikasi Rapirminer. In Data Mining, Teori dan Aplikasi Rapirminer. 